\title{
Cytoplasmic vacuolation of peripheral blood cells in acute alcoholism
}

\author{
RJ DAVIDSON AND JL MCPHIE
}

From the Haematology Unit and Department of Pathology, University of Aberdeen, Foresterhill, Aberdeen $A B 92 Z D$, UK

SUMMARY Cytoplasmic vacuolation of peripheral blood leucocytes is reported in three patients with acute alcoholism. Apparently this is the first report of vacuolation of peripheral blood leucocytes associated with acute alcoholism. Apart from any direct cytotoxic effect of alcohol the metabolic acidosis and hypoglycaemia associated with acute alcoholic poisoning may be important factors in the pathogenesis of the morphological changes.

The association of alcoholism with reversible vacuolation of red cell and, less consistently, white cell marrow precursors is well recognised. ${ }^{1}$ When experimentally induced by ethanol administration to human volunteers such vacuolation appears to be dose-related, and its development in the presence of folate supplementation and normoblastic haemopoiesis seems to indicate that it is due to a direct toxic effect of alcohol. ${ }^{2}$

We report, apparently for the first time, vacuolation in granulocytes and lymphocytes in the peripheral blood in three alcoholics, two of whom succumbed to acute alcoholic poisoning.

\section{Case reports}

CASE 1

A 38-year-old man with a long history of alcoholism was admitted to hospital after being found unconscious in his home after a bout of drinking thought to have lasted for six days. On admission he was comatose and his blood pressure unrecordable. The blood alcohol concentration measured some 36 hours later was still $1200 \mathrm{mg} / \mathrm{l}$. Examination of the cerebrospinal fluid (CSF) was normal. Clinically he was diagnosed as having acute liver failure with hypoglycaemia and metabolic acidosis. Confirmatory biochemical results included arterial blood $\mathrm{pH}$ 7.14; serum bilirubin $66 \mu \mathrm{mol} / 1$; aspartate amino transferase $($ AAT) $>100 \mathrm{IU} / \mathrm{l}$; alkaline phosphatase $115 \mathrm{IU} / 1$; plasma glucose $<1.2 \mathrm{mmol} / 1$; blood lactate $65.3 \mathrm{mg} / \mathrm{l}$ and pyruvate $22.5 \mathrm{mg} / \mathrm{l}$. The

Received for publication 6 May 1980
Coulter S peripheral blood profile showed WBC $7.0 \times 10^{9} / 1$, RBC $3.3 \times 10^{12} / 1$, Hb $10.8 \mathrm{~g} / \mathrm{dl}$, PCV $0 \cdot 37$, MCV $111 \mathrm{fl}, \mathrm{MCH} 33 \mathrm{pg}$, and MCHC $29 \mathrm{~g} / \mathrm{dl}$. Platelets were $79 \times 10^{9} / 1$ and reticulocytes $4.2 \%$. The differential WBC comprised neutrophils $74 \%$, lymphocytes $22 \%$, monocytes $4 \%$. On microscopy the red cells were generally normochromic but included some round macrocytes. Polychromatic forms were increased and of the occasional late normoblasts detected some contained multiple cytoplasmic vacuoles (Fig. d). Neutrophils showed prominent cytoplasmic vacuolation but the usual accompanying features of toxic or reactive changenamely, a nuclear shift to the left and toxic granulation-were absent. Vacuolation was also present in a significant number of monocytes and lymphocytes (Table).

After intravenous electrolyte and fluid replacement his systolic BP rose to $100 \mathrm{~mm} \mathrm{Hg}$ and his depth of unconsciousness lightened. But he remained anuric and died some 24 hours after admission. Necropsy 20 hours after death revealed subcutaneous crepitus of neck, shoulder, and scrotal tissues. Both lungs were grossly oedematous. The liver $(2100 \mathrm{~g})$ was pale and fatty and its cut surface showed a micronodular cirrhotic pattern. Both kidneys displayed cortical pallor and the terminal ileum showed a $5-\mathrm{cm}$ long segment of congestion with subserosal gas bubbles. Histological examination confirmed the presence of pulmonary oedema, an active micronodular hepatic cirrhosis, and bilateral renal cortical necrosis. Staining by the Oil-Red-O technique showed severe fatty change in hepatocytes, focal fatty vacuolation of subendocardial muscle fibres, 


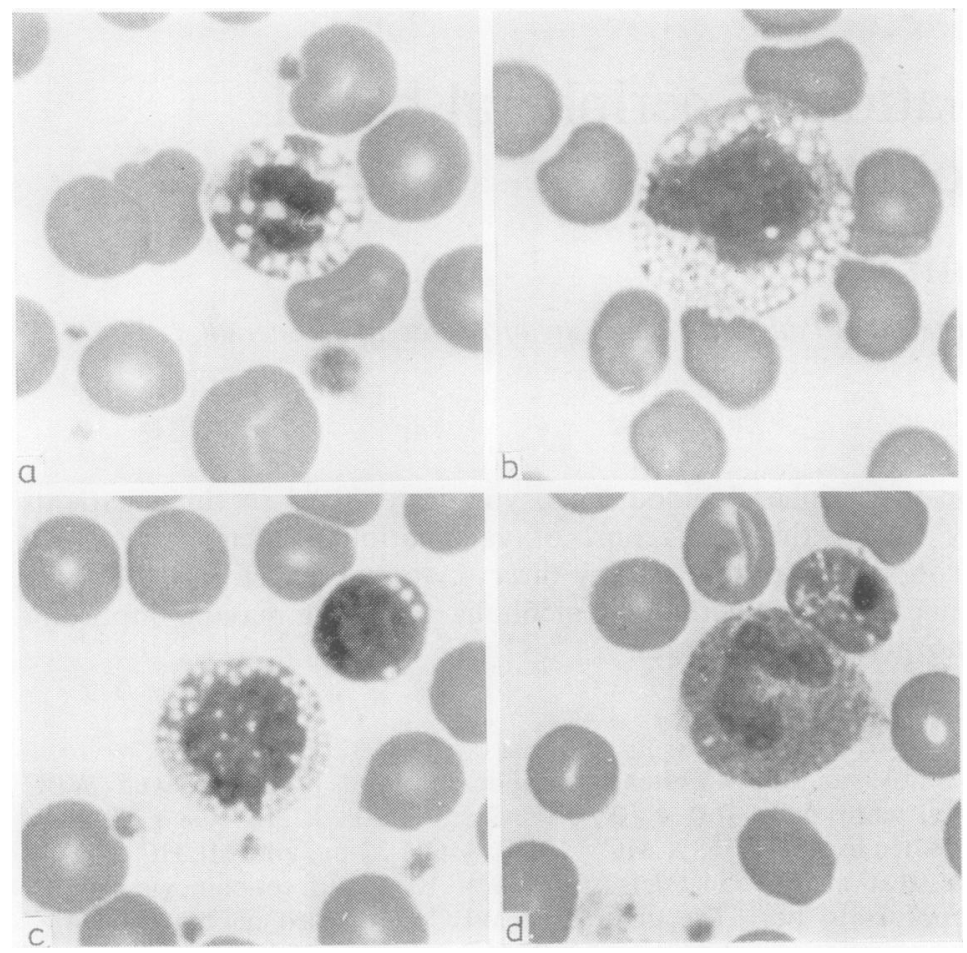

Vacuolation of peripheral blood cells in (a) neutrophil, (b) monocyte. (c) monocyte and lymphocyte, and (d) nucleated red cell adjacent to non-vacuolated 'band' neutrophil (magnification $\times 1000)$.

Distribution of vacuolated peripheral blood leucocytes

\begin{tabular}{llll}
\hline Case No. & \multicolumn{2}{l}{ Vacuolated cells $(\%)$} & Lymphocytes \\
\cline { 2 - 4 } & Neutrophils & Monocytes & 52 \\
1 & 56 & 80 & 44 \\
2 & 64 & 65 & 4 \\
3 & 26 & 15 & $<1$ \\
Normal range & & $<5$ & 1 \\
\hline
\end{tabular}

and fat accumulation in proximal renal tubular cells. Swabs taken from the spleen yielded a growth of Clostridium welchii.

CASE 2

A 32-year-old married woman with a long and tragic history of alcohol abuse had had several previous hospital admissions because of episodes of delirium tremens or liver failure. Her final admission was after she was found unconscious in her home after a bout of drinking of uncertain duration. She was moribund, BP $70 / 50 \mathrm{~mm} \mathrm{Hg}$, deeply jaundiced, and her blood alcohol concentration was $990 \mathrm{mg} / \mathrm{l}$. She was diagnosed as suffering from acute-on-chronic alcoholinduced liver damage with encephalopathy, metabolic acidosis, and hypoglycaemia. Biochemical findings included standard bicarbonate $17 \mathrm{mmol} / \mathrm{l}$; urea $8.4 \mathrm{mmol} / \mathrm{l}$; plasma glucose $<1.0 \mathrm{mmol} / \mathrm{l}$; serum bilirubin $123 \mu \mathrm{mol} / \mathrm{l}$; AAT $470 \mathrm{IU} / \mathrm{l}$, and alkaline phosphatase $188 \mathrm{IU} / \mathrm{l}$. The Coulter $\mathrm{S}$ peripheral blood profile was WBC $11.7 \times 10^{9} / 1, \mathrm{RBC} 3.1 \times$ $10^{12} / \mathrm{l}, \mathrm{Hb} 10.8 \mathrm{~g} / \mathrm{dl}$, PCV 0.33, MCV $106 \mathrm{fl}, \mathrm{MCH}$ $36 \mathrm{pg}, \mathrm{MCHC} 33 \mathrm{~g} / \mathrm{dl}$. Platelets were $96 \times 10^{9} / 1$ and reticulocytes $4 \%$. The differential WBC comprised neutrophils $75 \%$, lymphocytes $18 \%$, monocytes $5 \%$, and eosinophils $2 \%$. On microscopy the red cells were normochromic but included some round macrocytes and stomatocytes. Neutrophils showed prominent cytoplasmic vacuolation with toxic granular change but no accompanying nuclear shift to the left. Vacuolation was again noted in many monocytes and lymphocytes (Table).

Despite intensive resuscitative measures the patient died within 18 hours of admission. Necropsy 39 hours after death revealed patchy haemorrhages in both upper lung lobes, oesophageal varices, splenic enlargement $(280 \mathrm{~g})$ with congestion, and a fatty liver $(1350 \mathrm{~g})$ with a pattern of micronodular cirrhosis. Histological examination confirmed pulmonary oedema and focal haemorrhages consistent with aspiration of blood, splenic changes of portal hypertension, a micronodular cirrhosis with marked 
cholestasis, and alcoholic hepatitis. Lipid staining again revealed gross fatty change within hepatocytes, focal fatty degeneration of myocardial fibres, and fatty vacuolation of proximal renal tubular cells.

\section{CASE 3}

A 53-year-old woman office cleaner was admitted as an emergency after being found at work in a collapsed and confused state. She had a history of alcoholic abuse for one year. When she arrived for work on the day of her admission to hospital she was seen to be 'shaky and trembling'. On arrival in the casualty department she was confused and aggressive with delusional features consistent with an alcohol withdrawal syndrome despite an absence of alcohol in the blood. An empty whisky bottle was found in her bag. After treatment and surveillance in a medical ward for 48 hours her behaviour necessitated her transfer to a psychiatric unit for further treatment of her withdrawal symptoms.

The biochemical profile included normal plasma electrolytes and urea; blood glucose $4.8 \mathrm{mmol} / \mathrm{l}$; serum bilirubin $11 \mu \mathrm{mol} / \mathrm{l}$; AAT $84 \mathrm{IU} / \mathrm{l}$; alkaline phosphatase $80 \mathrm{IU} / \mathrm{l}$, and gamma-glutamyl-transferase $28 \mathrm{U} / 1$. Skull and chest radiographs, brain scan, and blood cultures were all normal. The Coulter $\mathrm{S}$ peripheral blood profile revealed WBC $5.7 \times 10^{9} / \mathrm{I}$, RBC $4.0 \times 10^{12} / 1, \mathrm{Hb} 12.5 \mathrm{~g} / \mathrm{dl}, \mathrm{PCV} \mathrm{0.4}, \mathrm{MCV}$ $101 \mathrm{fl}, \mathrm{MCH} 31 \mathrm{pg}, \mathrm{MCHC} 31 \mathrm{~g} / \mathrm{dl}$. Platelets were $139 \times 10^{9} / 1$ and reticulocytes $2 \%$. The differential WBC comprised neutrophils $77 \%$, lymphocytes $17 \%$, monocytes $5 \%$, and eosinophils $1 \%$. On microscopy the red cells were normochromic but included some round macrocytes and stomatocytes with very occasional target cells. Neutrophils again showed prominent cytoplasmic vacuolation without a nuclear shift to the left or toxic granular change. A smaller number of monocytes and lymphocytes displayed vacuolar change (Table).

\section{Discussion}

The vacuolation of bone-marrow cells in acute alcoholism is reversible, occurs predominantly in red cell precursors, affects early rather than late forms (mainly pronormoblasts and promyelocytes), and the cytoplasmic rather than nuclear component. ${ }^{3}$ These changes have also been noted in marrow cells of premature infants born to mothers who had had intravenous alcohol administered to delay the onset of labour. ${ }^{4}$ The vacuoles do not stain positively for fat, mucopolysaccharide, DNA, RNA, peroxidase, or acid and alkaline phosphatase. ${ }^{2}$ Similar marrow vacuoles have been reported in association with chloramphenicol administration, ${ }^{5}$ in experi- mentally induced riboflavine ${ }^{6}$ and phenylalanine deficiency, ${ }^{7}$ and in the course of treatment of phenylketonuria. ${ }^{8}$ Riboflavine or phenylalanine deficiency is not thought to be involved in the formation of vacuolation in acute alcoholism. ${ }^{9}$ Cytoplasmic and nuclear vacuolation of only red cell precursors may be prominent in erythraemic myelosis, ${ }^{10}$ while their presence in only the primitive white cells is usual in bone marrow involvement in Burkitt's lymphoma ${ }^{11}$ and occasional in acute leukaemias.

Unfortunately we were unable to ascertain the marrow cytology in our patients and hence to compare any changes with those in peripheral blood. In cases 1 and 2 the marrow obtained at necropsy was too autolysed for valid study, while marrow aspiration was not attempted in case 3 because of the patient's disturbed mental state. In the peripheral blood degenerative vacuolation of neutrophils, monocytes, and lymphocytes may be discernible in the stained film when prepared from blood which has been allowed to stand, particularly at room temperature, for more than three hours after collection. ${ }^{12}$ Vacuolation of neutrophils and monocytes is most commonly associated with infective, especially septicaemic, states ${ }^{13}$ and toxic conditions including metabolic disturbances such as diabetic ketoacidosis. ${ }^{14}$ Similar vacuolar changes have also been reported in progressive muscular dystrophy. ${ }^{15}$ In contrast, vacuolation of peripheral blood lymphocytes is unusual and apart from its occasional presence in viral infections, including infectious mononucleosis, it is, as described, ${ }^{16}$ virtually limited to a number of rare hereditary disorders-sphingomyelin lipidosis (Niemann-Pick disease), ganglioside lipidosis (Tay-Sach and Batten-Spielmeyer-Vogt diseases), type II glycogen storage disease (Pompe's disease), and genetic mucopolysaccharidosis (Hurler-Hunter syndrome).

Both quantitative and functional granulocytic changes with predisposition to infection are well documented in alcoholics ${ }^{17}$ and in case 1 we cannot exclude that clostridial infection contributed to the leucocyte and red cell changes, although its detection only at necropsy 20 hours after death favours an agonal event. In cases 2 and 3, however, there was no clinical or laboratory evidence of infection and we could not therefore attribute the leucocyte changes to any of the aforementioned causes other than direct toxicity or the metabolic disturbances induced by the acute alcoholism. This conclusion is supported by recent reviews which have not only incriminated alcohol as a direct haematotoxin ${ }^{18} 19$ but suggested that the pathogenesis of its effects on haemopoietic cells may not be different from that on any other body cell or tissue. ${ }^{20}$ Our present findings not only support this concept but extend the 
spectrum of cytotoxic change to include peripheral blood leucocytes and in severe cases even the mature red cell.

We would further postulate that, apart from the direct' toxic effect of alcohol and its metabolites, the metabolic acidosis and hypoglycaemia ${ }^{21}$ induced by acute alcoholism may be important factors contributing to the cell damage by impairing and, in severe cases, largely inhibiting glycolysis and other metabolic processes essential to normal cell function and membrane integrity. Such a sequence of events is analogous to that in diabetic ketoacidosis where a similar spectrum of morphological and functional change may be manifest in different tissues or cells ranging from cloudy swelling to fatty vacuolation in hepatocytes and toxic granulation to vacuolation in peripheral blood neutrophils. ${ }^{14}$

Finally, our observations of vacuolar change in peripheral blood leucocytes is supported by experimental studies in $\operatorname{dogs}^{22}$ fed varying amounts of alcohol and where marked cytoplasmic vacuolation and nuclear pyknosis were not only noted in both peripheral blood lymphocytes and granulocytes but the frequency and degree of these morphological changes were clearly dose-related.

We thank Dr AM Lessells for the necropsy report in case 1 and several of our clinical colleagues for permission to publish details of patients under their care.

\section{References}

${ }^{1}$ McCurdy PR, Pierce LE, Rath CE. Abnormal bonemarrow morphology in acute alcoholism. $N$ Engl $J$ Med 1962;266:505-7.

${ }^{2}$ Lindenbaum J, Lieber CS. Haematologic effects of alcohol in man in the absence of nutritional deficiency. $N$ Engl $J$ Med 1969;28:333-8.

${ }^{3}$ Jarrold T, Will JJ, Davies AR, Duffey PH, Bramschreiber JL. Bone marrow-erythroid morphology in alcoholic patients. Am J Clin Nutr 1967;20:716-22.

${ }^{4}$ Lopez R, Montoya MF. Abnormal bone marrow morphology in the premature infant associated with maternal alcohol infusion. $J$ Pediatr 1971;79:1008-10.

${ }^{5}$ McCurdy PR. Chloramphenicol bone marrow toxicity. JAMA 1961;176:588-93.

- Lane M, Alfrey CP. The anaemia of human riboflavin deficiency. Blood $1965 ; 25: 432-42$.

7 Cockburn F, Sherman JD, Ingall D, Klein R. Effect of phenylalanine deficient diet on bone marrow and amino acid metabolism. Proc Soc Exp Biol Med 1965;118:238-45.

${ }^{8}$ Sherman JD, Greenfield JB, Ingall D. Reversible bonemarrow vacuolizations in phenylketonuria. $N$ Engl $J$ Med 1964;270:810-4.

9 Waters AH, Morley AA, Rankin JG. Effect of alcohol on haemopoiesis. Br Med J 1966;ii:1565-8.

10 Riddell EM, Davidson RJL. Co-existence of pernicious anaemia and acute erythaemic myelosis. $J$ Clin Pathol $1968 ; 21: 590-4$.

${ }^{11}$ Bluming AZ, Ziegler JL, Carbone PP. Bone marrow involvement in Burkitt's lymphoma: results of a prospective study. Br J Haematol 1972;22:369-76.

12 Dacie JV, Lewis SM. Practical Haematology. 5th edn. London: Churchill Livingstone, 1975.

${ }^{13}$ Ponder E, Ponder RV. Cytology of polymorphonuclear leucocyte in toxic conditions. J Lab Clin Med 1942; 28:316-22.

${ }^{14}$ Gordin R. Toxic granulation in leukocytes; development and relation to cloudy swelling. Acta Med Scand (Suppl 270) $1952 ; 143: 1-50$.

15 Jordans GHW. The familial occurrence of fat containing vacuoles in the leucocytes diagnosed in 2 brothers suffering from dystrophia musculorum progressiva. Acta Med Scand 1953;145:419-23.

16 Brunning MD. Morphologic alterations in nucleated blood and marrow cells in genetic disorders. Human Pathol $1970 ; 1: 99-124$.

17 Eichner ER. The haematologic disorders of alcoholism. Am J Med 1973;54:621-30.

${ }^{18}$ Anonymous. Blood in the alcohol stream. Lancet 1977; ii $: 806$.

${ }^{19}$ Anonymous. Alcohol and the blood. $\mathrm{Br}$ Med $J$ 1978; i:1504-5.

${ }^{20}$ Chanarin I. Alcohol and the blood. Br J Haematol 1979; 42:333-6.

${ }^{21}$ Marks V. Alcohol and carbohydrate metabolism. Clin Endocrinol Metab 1978;7:333-49.

${ }^{22}$ Beard JD, Knott DH. Hemopoietic response to experimental chronic alcoholism. Amer J Med Sci 1966; 252:518-25.

Requests for reprints to: Dr RJ Davidson, Haematology Unit, Department of Pathology, University Medical Buildings, Foresterhill, Aberdeen AB9 2ZD. 